\title{
The Protective Role of HLA-DRB1*13 in Autoimmune Diseases
}

\author{
Andreia Bettencourt, ${ }^{1,2}$ Cláudia Carvalho, ${ }^{1,2}$ Bárbara Leal, ${ }^{1,2}$ Sandra Brás, ${ }^{1}$ Dina Lopes, \\ Ana Martins da Silva, ${ }^{2,3,4}$ Ernestina Santos, ${ }^{2,3}$ Tiago Torres, ${ }^{2,5}$ Isabel Almeida, ${ }^{2,4}$ \\ Fátima Farinha, ${ }^{2,4,6}$ Paulo Barbosa, ${ }^{2}$ António Marinho, ${ }^{2,4}$ Manuela Selores, ${ }^{5}$ \\ João Correia, ${ }^{2,4,6}$ Carlos Vasconcelos, ${ }^{2,4}$ Paulo P. Costa, ${ }^{1,2,7}$ and Berta Martins da Silva ${ }^{1,2}$ \\ ${ }^{1}$ Immunogenetics Laboratory, Instituto de Ciências Biomédicas Abel Salazar-Universidade do Porto (ICBAS-UP), \\ Rua de Jorge Viterbo Ferreira No. 228, 4050-313 Porto, Portugal \\ ${ }^{2}$ Unit for Multidisciplinary Research in Biomedicine (UMIB), Abel Salazar Institute of Biomedical Sciences (ICBAS), \\ University of Porto (UP), Rua de Jorge Viterbo Ferreira No. 228, 4050-313 Porto, Portugal \\ ${ }^{3}$ Department of Neurology, Centro Hospitalar do Porto-Hospital de Santo António (CHP-HSA), \\ Largo Prof. Abel Salazar, 4099-001 Porto, Portugal \\ ${ }^{4}$ Unidade de Imunologia Clínica (UIC), Centro Hospitalar do Porto-Hospital de Santo António (CHP-HSA), \\ Largo Prof. Abel Salazar, 4099-001 Porto, Portugal \\ ${ }^{5}$ Department of Dermatology, Centro Hospitalar do Porto-Hospital de Santo António (CHP-HSA), \\ Largo Prof. Abel Salazar, 4099-001 Porto, Portugal \\ ${ }^{6}$ Department of Internal Medicine, Centro Hospitalar do Porto-Hospital de Santo António (CHP-HSA), \\ Largo Prof. Abel Salazar, 4099-001 Porto, Portugal \\ ${ }^{7}$ Instituto Nacional de Saúde Dr. Ricardo Jorge (INSA), Rua Alexandre Herculano No. 321, 4000-055 Porto, Portugal
}

Correspondence should be addressed to Berta Martins da Silva; bertams@icbas.up.pt

Received 10 August 2015; Accepted 20 October 2015

Academic Editor: Carlo Perricone

Copyright (C) 2015 Andreia Bettencourt et al. This is an open access article distributed under the Creative Commons Attribution License, which permits unrestricted use, distribution, and reproduction in any medium, provided the original work is properly cited.

Autoimmune diseases (AIDs) are characterized by a multifactorial aetiology and a complex genetic background, with the MHC region playing a major role. We genotyped for HLA-DRB1 locus 1228 patients with AIDs-213 with Systemic Lupus Erythematosus (SLE), 166 with Psoriasis or Psoriatic Arthritis (Ps + PsA), 153 with Rheumatoid Arthritis (RA), 67 with Systemic Sclerosis (SSc), 536 with Multiple Sclerosis (MS), and 93 with Myasthenia Gravis (MG) and 282 unrelated controls. We confirmed previously established associations of HLA-DRB1* $15(\mathrm{OR}=2.17)$ and HLA-DRB1* 03 (OR $=1.81)$ alleles with MS, HLA-DRB1 ${ }^{*} 03$ with SLE $(\mathrm{OR}=2.49)$, HLA-DRB1* $01(\mathrm{OR}=1.79)$ and HLA-DRB1* $04(\mathrm{OR}=2.81)$ with RA, HLA-DRB1*07 with Ps + PsA $(\mathrm{OR}=1.79), \mathrm{HLA}-$ DRB1 $^{*} 01(\mathrm{OR}=2.28)$ and HLA-DRB1* $08(\mathrm{OR}=3.01)$ with SSc, and HLA-DRB1* 03 with MG $(\mathrm{OR}=2.98)$. We further observed a consistent negative association of HLA-DRB1 ${ }^{*} 13$ allele with SLE, Ps + PsA, RA, and SSc (18.3\%, 19.3\%, 16.3\%, and 11.9\%, resp., versus $29.8 \%$ in controls). HLA-DRB1* 13 frequency in the AIDs group was $20.0 \%(\mathrm{OR}=0.58)$. Although different alleles were associated with particular AIDs, the same allele, HLA-DRB1*13, was underrepresented in all of the six diseases analysed. This observation suggests that this allele may confer protection for AIDs, particularly for systemic and rheumatic disease. The protective effect of HLA-DRB1* 13 could be explained by a more proficient antigen presentation by these molecules, favouring efficient clonal deletion during thymic selection.

\section{Introduction}

Autoimmune diseases (AIDs) are chronic disorders originated by the loss of immunological tolerance to self-antigens. This heterogeneous group of conditions present common genetic risk factors and share several pathophysiological mechanisms leading to overlapping clinical manifestations targeting specific organs or multiple organ systems [1]. There is evidence that they share similar immunogenetic mechanisms, even though they exhibit varying epidemiological features and clinical manifestations $[2,3]$. Underlying these diverse clinical phenotypes is a deregulated immune system 
with an enriched ability to respond against self-tissues. The fact that AIDs share several clinical signs and symptoms (i.e., subphenotypes) and also share physiopathological mechanisms and genetic factors has been called autoimmune tautology and indicates that they may have a common origin [4].

The immune system is in charge of the defence against external pathogens. For this purpose, $\mathrm{T}$ and B lymphocytes are responsible for the immune response through regulated cell-cell interactions and secretion of cytokines, chemokines, and other inflammatory mediators. This defence against external pathogens must occur without causing unnecessary harm to self. To achieve this delicate balance, the majority of self-reactive $\mathrm{T}$ and $\mathrm{B}$ lymphocytes are destroyed in the thymus and bone marrow through negative selection [5]. Nevertheless, this process is far from perfect, and self-reactive lymphocytes escape into the periphery. Consequently, peripheral tolerance mechanisms are necessary to keep these selfreactive cells in check [6]. Activated self-reactive $\mathrm{T}$ and $\mathrm{B}$ cells promote autoimmunity when the effector and regulatory balance of the immune response is disturbed [7].

Major histocompatibility complex (MHC) molecules are widely distributed surface membrane glycoproteins that present antigenic peptides to T cell receptors (TCRs). Developing thymocytes encounter a highly heterogeneous repertoire of self (endogenous) peptide-MHC (pMHC) complexes on thymic epithelial cells, the main thymus antigen presenting cells. The affinity/avidity with which these thymocyte TCRs bind self pMHC determines if it is destined to perish or if it will survive [8]. In this way, a repertoire of peripheral T cells that is essentially self-tolerant is generated $[6,9,10]$.

Several hypotheses have been put forward to explain how MHC polymorphisms influence autoimmunity risk or protection. They must do so, somehow, by shaping the central or peripheral $\mathrm{T}$ cell repertoires toward autoimmune resistance or proclivity [8]. A protective MHC profile could achieve this by the selection of a $\mathrm{T}$ cell repertoire with diminished pathogenicity [11]. On the other hand, protective MHC molecules may keep autoimmunity in check by favouring the negative selection of particular self-reactive T cells [12-14].

The functional basis of the association between specific HLA alleles and development of AIDs can be classically explained by two possible etiopathogenic models [15].

The molecular mimicry hypothesis proposes that certain HLA alleles are more efficient in presenting pathogen epitopes that share structural features with self-peptides to mature $\mathrm{T}$ cells. Once the response to the pathogen is initiated the self-antigen is also recognized and disease ensues.

Central selection failure proposes that certain HLA alleles are less efficient at presenting self-peptides to developing $\mathrm{T}$ cells in the thymus, so negative selection fails.

A different hypothesis proposes that different alleles can modulate the immunologic profile of an individual, through antigen-independent mechanisms, resulting in either promoting a higher autoimmune predisposition or, in opposition, a more efficient immune regulation. Given the consistent association of HLA-DRB1 alleles with different autoimmune diseases (Table 1), we explored the idea that the same HLA-DRB1 alleles could be influencing several different autoimmune diseases. To this end we compared the immunogenetic profile in different AIDs. This study includes four autoimmune systemic diseases, namely, Systemic Lupus Erythematosus (SLE), Rheumatoid Arthritis (RA), Psoriasis or Psoriatic Arthritis (Ps + PsA), and Systemic Sclerosis (SSc). Patients with Multiple Sclerosis (MS) and Myasthenia Gravis (MG) were also included.

\section{Patients and Methods}

2.1. Patients and Controls. A total of 1228 patients with AIDs, 213 patients with SLE and 153 patients with RA diagnosed according to the American College of Rheumatology (ACR) criteria, 166 patients with Ps + PsA, 67 with SSc, 536 with definitive diagnosis of MS according to the revised McDonald criteria, and 93 with MG, were recruited from the Neurology and Medicine Outpatient Clinic of Centro Hospitalar do Porto-Hospital de Santo António (CHP-HSA). The HLADRB1 frequencies of patients were compared with the ones of a control group consisting of 282 unrelated individuals without disease and from the same geographic origin (north of Portugal).

2.2. HLA-DRB1 Genotyping. Peripheral blood samples $(10 \mathrm{~mL})$ were collected in EDTA. Genomic DNA was obtained from proteinase-K-treated peripheral blood leukocytes by using a Salting-Out procedure [27]. Low-resolution genotyping for HLA-DRB1 locus (i.e., 2-digit HLA nomenclature) was performed using polymerase chain reaction and sequence-specific primers (PCR-SSP), based on methods previously described [28]. In order to produce PCR-SSP reactions able to detect and discriminate each of the known HLADRB1 genes, primers were designed using sequence alignments comprising all HLA-DRB1 variants and were validated by the Twelfth International Histocompatibility Workshop. PCR products were visualized under ultraviolet light after running in a $1.5 \%$ agarose gel containing ethidium bromide.

2.3. Statistical Analysis. To identify the HLA-DRB1 genes contributing to the six different AIDs, we applied stepwise logistic regression on an allelic level, using forward selection which involves starting with no variables in the model, testing the addition of each variable using a chosen model comparison criterion, adding the variable (if any) that improves the model the most, and repeating this process until none improves the model. It should be noted that odds ratios (ORs) obtained in a multivariable logistic regression analysis are adjusted for all the other genes included in the model and therefore differ from those obtained when a given gene is compared with all other genes. The data were analysed using IBM SPSS 20 statistical software.

\section{Results}

A total of 1228 cases and 282 controls were analysed and different types of association between alleles and AIDs were found (Table 2). These included three risk alleles for two or more AIDs, two protective alleles for two or more AIDs, and three risk alleles for a particular AID. 
TABLE 1: HLA-DRB1 alleles associated with SLE, Ps + PsA, RA, SSc, MS, and MG.

\begin{tabular}{|c|c|c|c|}
\hline \multirow{2}{*}{ Autoimmune disease } & \multicolumn{2}{|c|}{ HLA-DRB1 associated allele } & \multirow{2}{*}{ References } \\
\hline & Susceptibility & Protection & \\
\hline $\begin{array}{l}\text { Systemic Lupus } \\
\text { Erythematosus (SLE) }\end{array}$ & $\begin{array}{l}\text { HLA-DRB1 }^{*} 03 \\
\text { HLA-DRB1 }^{*} 08 \\
\text { HLA-DRB1 }^{*} 15\end{array}$ & $\begin{array}{l}\text { HLA-DRB1 }{ }^{*} 09 \\
\text { HLA-DRB1 }^{*} 13\end{array}$ & [16-18] \\
\hline $\begin{array}{l}\text { Psoriasis or Psoriatic Arthritis } \\
\text { (Ps + PsA) }\end{array}$ & HLA-DRB1* 07 & - & {$[19,20]$} \\
\hline Rheumatoid Arthritis (RA) & $\begin{array}{l}\text { HLA-DRB1 }^{*} 01 \\
\text { HLA-DRB1 }^{*} 04 \\
\text { HLA-DRB1 }\end{array}$ & HLA-DRB1*13 & {$[21]$} \\
\hline Systemic Sclerosis (SSc) & $\begin{array}{l}\text { HLA-DRB1 }^{*} 01 \\
\text { HLA-DRB1 }^{*} 08 \\
\text { HLA-DRB1 }^{*} 11\end{array}$ & $\begin{array}{l}\text { HLA-DRB1* } 07 \\
\text { HLA-DRB1 }^{*} 15\end{array}$ & {$[22,23]$} \\
\hline Multiple Sclerosis (MS) & $\begin{array}{l}\text { HLA-DRB1 }^{*} 03 \\
\text { HLA-DRB1 }^{*} 08 \\
\text { HLA-DRB1 } \\
\end{array}$ & $\begin{array}{l}\text { HLA-DRB1 }{ }^{*} 10 \\
\text { HLA-DRB1 }{ }^{*} 14\end{array}$ & {$[24,25]$} \\
\hline Myasthenia Gravis (MG) & HLA-DRB1* 03 & - & {$[26]$} \\
\hline
\end{tabular}

TABle 2: Associations between HLA class II and six AIDs: SLE, Ps + PsA, RA, SSc, MS, and MG.

\begin{tabular}{|c|c|c|c|c|c|c|c|c|}
\hline & $\begin{array}{c}\text { Controls } \\
(n=282)\end{array}$ & $\begin{array}{c}\text { SLE } \\
(n=213)\end{array}$ & $\begin{array}{l}\text { Ps + PsA } \\
(n=166)\end{array}$ & $\begin{array}{c}\text { RA } \\
(n=153)\end{array}$ & $\begin{array}{c}\text { SSc } \\
(n=67)\end{array}$ & $\begin{array}{c}\text { MS } \\
(n=536)\end{array}$ & $\begin{array}{c}\text { MG } \\
(n=93)\end{array}$ & $\begin{array}{c}\text { Total } \\
(n=1228)\end{array}$ \\
\hline HLA-DRB1 ${ }^{*} 01$ & $66(23.4 \%)$ & $40(18.8 \%)$ & $39(23.5 \%)$ & $\begin{array}{c}50(32.7 \%) \\
O R=1.79 \\
p=0.017 \\
\end{array}$ & $\begin{array}{c}28(41.8 \%) \\
O R=2.28 \\
p=0.006\end{array}$ & $100(18.7 \%)$ & $23(24.7 \%)$ & $280(22.8 \%)$ \\
\hline HLA-DRB1*03 & $44(15.6 \%)$ & $\begin{array}{c}73(34.3 \%) \\
\text { OR }=2.49 \\
p=4.2 \times 10^{-5}\end{array}$ & $25(15.1 \%)$ & $28(18.3 \%)$ & $11(16.4 \%)$ & $\begin{array}{c}123(22.9 \%) \\
\text { OR }=1.81 \\
p=0.003\end{array}$ & $\begin{array}{c}33(35.5 \%) \\
\text { OR }=2.98 \\
p=6.1 \times 10^{-5}\end{array}$ & $\begin{array}{c}293(23.9 \%) \\
\text { OR }=1.51 \\
p=0.022\end{array}$ \\
\hline HLA-DRB1*04 & $69(24.5 \%)$ & $42(19.7 \%)$ & $46(27.7 \%)$ & $\begin{array}{c}73(47.7 \%) \\
\text { OR }=2.81 \\
p=6 \times 10^{-6}\end{array}$ & $13(19.4 \%)$ & $128(23.9 \%)$ & $23(24.7 \%)$ & $325(26.5 \%)$ \\
\hline HLA-DRB1 ${ }^{*} 07$ & $72(25.5 \%)$ & $55(25.8 \%)$ & $\begin{array}{c}66(39.8 \%) \\
O R=1.79 \\
p=0.006\end{array}$ & $38(24.8 \%)$ & $14(20.9 \%)$ & $147(27.4 \%)$ & $23(24.7 \%)$ & $343(27.9 \%)$ \\
\hline HLA-DRB1 ${ }^{*} 08$ & $24(8.5 \%)$ & $21(10.0 \%)$ & $10(6.0 \%)$ & $\begin{array}{c}3(2.0 \%) \\
\text { OR }=0.24 \\
p=0.026\end{array}$ & $\begin{array}{c}15(22.4 \%) \\
O R=3.01 \\
p=0.004\end{array}$ & $\begin{array}{c}65(12.1 \%) \\
O R=1.73 \\
p=0.033 \\
\end{array}$ & $7(7.5 \%)$ & $121(9.9 \%)$ \\
\hline HLA-DRB1 ${ }^{*} 09$ & $14(5.0 \%)$ & $\begin{array}{c}2(1.0 \%) \\
O R=0.18 \\
p=0.027\end{array}$ & $5(3.0 \%)$ & $\begin{array}{c}0(0.0 \%)^{*} \\
\mathrm{OR}=0.95 \\
\mathrm{p}=\mathbf{0 . 0 0 3}\end{array}$ & $3(4.5 \%)$ & $\begin{array}{c}5(1.0 \%) \\
O R=0.22 \\
p=0.004\end{array}$ & $2(2.2 \%)$ & $\begin{array}{c}17(1.4 \%) \\
O R=0.23 \\
p=1 \times 10^{-4}\end{array}$ \\
\hline HLA-DRB1 ${ }^{*} 13$ & $84(29.8 \%)$ & $\begin{array}{c}39(18.3 \%) \\
\text { OR }=0.58 \\
p=0.016\end{array}$ & $\begin{array}{r}32(19.3 \%) \\
O R=0.62 \\
p=0.050\end{array}$ & $\begin{array}{l}25(16.3 \%) \\
O R=0.58 \\
p=0.044\end{array}$ & $\begin{array}{r}8(11.9 \%) \\
\text { OR }=0.42 \\
p=0.035\end{array}$ & $124(23.1 \%)$ & $17(18.3 \%)$ & $\begin{array}{c}245(20.0 \%) \\
\text { OR }=0.58 \\
p=0.004\end{array}$ \\
\hline HLA-DRB1 ${ }^{*} 15$ & $56(19.9 \%)$ & $55(25.8 \%)$ & $22(13.3 \%)$ & $17(11.1 \%)$ & $12(17.9 \%)$ & $\begin{array}{c}175(32.7 \%) \\
O R=2.17 \\
p=2 \times 10^{-5}\end{array}$ & $15(16.1 \%)$ & $296(24.1 \%)$ \\
\hline
\end{tabular}

AIDs: autoimmune diseases; SLE: Systemic Lupus Erythematosus; Ps + PsA: Psoriasis or Psoriatic Arthritis; RA: Rheumatoid Arthritis; SSc: Systemic Sclerosis; MS: Multiple Sclerosis; MG: Myasthenia Gravis. ${ }^{*}$ Fisher's exact test was used to calculate this value.

HLA-DRB ${ }^{*} 13$ was a protective allele for four AIDs: SLE $(18.3 \%$ versus $29.8 \%, p=0.016$, $\mathrm{OR}=0.58$, and $95 \% \mathrm{CI}=$ $0.37-0.90)$, Ps + PsA (19.3\% versus $29.8 \%, p=0.050, \mathrm{OR}=$ 0.621 , and $95 \% \mathrm{CI}=0.39-1.00)$, RA ( $16.3 \%$ versus $29.8 \%, p=$ $0.044, \mathrm{OR}=0.58$, and $95 \% \mathrm{CI}=0.34-0.98)$, and SSc $(11.9 \%$ versus $29.8 \%, p=0.035, \mathrm{OR}=0.42$, and $95 \% \mathrm{CI}=0.19-0.94$ ).
There was a specific risk allele associated with three AIDs. HLA-DRB $1{ }^{*} 03$ was found to be a risk factor for SLE $(34.3 \%$ versus $15.6 \%, p=4.2 \times 10^{-5}, \mathrm{OR}=2.49$, and $95 \% \mathrm{CI}=$ $1.61-3.86)$, MS (22.9\% versus $15.6 \%, p=0.003$, OR $=1.81$, and $95 \% \mathrm{CI}=1.23-2.67)$, and MG (35.5\% versus $15.6 \%, p=$ $6.1 \times 10^{-5}, \mathrm{OR}=2.98$, and $\left.95 \% \mathrm{CI}=1.75-5.07\right)$. There were 
two risk alleles associated with two AIDs: HLA-DRB $1^{*} 08$ was positively associated with MS (12.1\% versus $8.5 \%, p=0.033$, $\mathrm{OR}=1.73$, and $95 \% \mathrm{CI}=1.05-2.87)$ and SSc (22.4\% versus $8.5 \%, p=0.004$, OR $=3.01$, and 95\% CI $=1.43-6.31)$ and HLA-DRB $1{ }^{*} 01$ was found to be a risk factor for RA $(32.7 \%$ versus $23.4 \%, p=0.017$, $\mathrm{OR}=1.79$, and $95 \% \mathrm{CI}=1.11-2.88)$ and SSc (41.8\% versus $23.4 \%, p=0.006, \mathrm{OR}=2.28$, and $95 \%$ $\mathrm{CI}=1.27-4.09$ ).

HLA-DRB ${ }^{*} 09$ was negatively associated with SLE (1.0\% versus $5.0 \%, p=0.027, \mathrm{OR}=0.18$, and $95 \% \mathrm{CI}=0.04-0.83)$, MS $(1.0 \%$ versus $5.0 \%, p=0.004, \mathrm{OR}=0.22$, and $95 \% \mathrm{CI}=$ $0.08-0.63)$, and RA ( $0.0 \%$ versus $1.0 \%, p=0.003$, OR $=0.95$, and $95 \% \mathrm{CI}=0.93-0.98)$.

Three risk disease-specific alleles were found: HLA$\mathrm{DRB}^{*} 04$ for RA $\left(47.7 \%\right.$ versus $24.5 \%, p=6 \times 10^{-6}, \mathrm{OR}=2.81$, and $95 \% \mathrm{CI}=1.79-4.39)$, HLA-DRB1 ${ }^{*} 07$ for Ps + PsA $(39.8 \%$ versus $25.5 \%, p=0.006, \mathrm{OR}=1.79$, and $95 \% \mathrm{CI}=1.18-2.72$ ), and HLA-DRB1 ${ }^{*} 15$ for MS (32.7\% versus $19.9 \%, p=2 \times 10^{-5}$, $\mathrm{OR}=2.17$, and $95 \% \mathrm{CI}=1.53-3.10)$.

Considering AIDs as a group, HLA-DRB1 ${ }^{*} 03$ frequency was significantly higher $(23.9 \%$ versus $15.6 \%, p=0.022$, $\mathrm{OR}=1.51$, and $95 \% \mathrm{CI}=1.0-2.15)$ compared with controls; conversely HLA-DRB1 ${ }^{*} 13(20.0 \%$ versus $29.8 \%, p=0.004$, $\mathrm{OR}=0.58$, and $95 \% \mathrm{CI}=0.43-0.79)$ and HLA-DRB1 ${ }^{*} 09$ $\left(1.4 \%\right.$ versus $5.0 \%, p=1 \times 10^{-4}, \mathrm{OR}=0.23$, and $95 \% \mathrm{CI}=$ 0.11-0.49) frequencies were significantly lower.

\section{Discussion}

Through a systematic review of published works, Cruz-Tapias and collaborators, in 2012, identified some common HLA class II alleles that contribute to susceptibility to AIDs in Latin Americans [3]. The present study is, to date and to the best of our knowledge, the only one that addresses the hypothesis that a HLA-DRB1 allele could influence different autoimmune diseases, using a new cohort, encompassing six different autoimmune diseases.

In this study we observed associations of different HLADRB1 alleles with several AIDs. We confirmed positive and negative associations in MS [24, 25], SLE [16-18], Ps + PsA [19, 20], RA [21], SSc [22, 23], and MG [26], previously reported in our or other populations.

When AIDs studied were considered as a group, HLA$\mathrm{DRB} 1{ }^{*} 03$ allele was significantly overrepresented, as already described [29]. It has been shown that this allele has low affinity for CLIP (class II-associated invariant chain peptide) and may not require HLA-DM to ensure peptide presentation, preventing efficient peptide selection and allowing the binding of low stability peptides [30]. Concerning the observed negative association with HLA-DRB $1^{*} 09$, we think that this is likely a spurious association, as this is a rare allele and the frequency found in controls is, for some reason, double the one reported for the Portuguese population [31].

Our observations suggest that the presence of HLADRB1*13 allele may confer protection for AIDs. HLA$\mathrm{DRB} 1{ }^{*} 13$ is a high frequency allele in the general population both in Portugal [31] and worldwide. Our results confirm that the lower frequency of HLA-DRB ${ }^{*} 13$ in every individual AIDs group is not secondary to the deviations granted by the concurrent positive associations. When the data obtained from previous studies are taken into consideration, the HLADRB $1^{*} 13$ allele seems to be a universal protective allele for RA. It was reported as protective against RA in Asian [32, 33], Turkish [34], and several European populations [35-37]. Recently this allele was also described to be protective in SLE in the Japanese population [18] and for ANCA-associated vasculitis in the Dutch population [38].

Subtle structural differences in the HLA molecule have functional implications at the protein level. Specific amino acid patterns at the peptide binding cleft are involved in disease susceptibility, such as the well-known shared epitope first described in the RA susceptibility alleles HLA-DRB ${ }^{*} 01$ and HLA-DRB1* 04 [37, 39]. Similar to the shared epitope classification of susceptibility alleles, protective HLA-DRB1 alleles have been categorized according to several models. One of the most accepted classifications proposes that protection against RA is conferred by the DERAA sequence at positions 70-74 of the HLA-DRB1 allele [40]. Other models suggest that protection is conferred by an aspartic acid at position 70 (D70 allele) [41] or an isoleucine at position 67 (I67 allele) of the HLA-DRB1 molecule. Because it was unclear which HLA-DRB1 alleles were protective a meta-analysis was performed involving four European populations with $>2,700$ patients and $>3,000$ control subjects. The objective was to investigate exhaustively which HLA-DRB1 alleles were associated with protection against RA [36]. Interestingly, this study showed that the protective effect attributed to DERAA and D70 was no longer present after the exclusion of HLA-DRB $1^{*} 13$. The authors concluded that this evidence indicates that HLA-DRB $1^{*} 13$ rather than DERAA, D70, or I67 is associated with protection [36]. In a recent study van Heemst and collaborators identify citrullinated vinculin, present in the joints of $\mathrm{ACPA}^{+} \mathrm{RA}$ patients, as an autoantigen targeted by ACPA and $\mathrm{CD} 4^{+} \mathrm{T}$ cells. These $\mathrm{T}$ cells recognize an epitope with the core sequence DERAA, which is also found in many microbes and in protective HLA-DRB1 ${ }^{*} 13$ molecules, presented by predisposing HLA-DQ molecules. Intriguingly, DERAA-directed T cells were not detected in HLA-DRB $1^{*} 13^{+}$donors, indicating that the DERAA epitope from HLA-DRB ${ }^{*} 13$ could mediate thymic tolerance in these donors and explain the protective effects associated with HLA-DRB1*13. They suggest that subjects born with HLADRB $1^{*} 13$ will present the HLA-DRB $1^{*} 13$-derived DERAApeptide in the thymus, leading to tolerization of the DERAAreactive $\mathrm{T}$ cell response [42]. The negative association we describe here supports the idea that the HLA-DRB1 ${ }^{*} 13$ allele, possibly by its specific structural features, may as well confer resistance to several other AIDs. The protective effect of HLA-DRB $1{ }^{*} 13$ could be explained by a more proficient antigen presentation by these molecules [43, 44], favouring an efficient thymic selection. As a result, negative selection and development of DR-driven autoreactive regulatory $\mathrm{T}$ cells are promoted [8].

A different model would relate HLA molecules with the presence of specific endophenotypes indirectly associated with autoimmunity. Other studies of our group suggest that the HLA genotype may primarily influence the general activation state of CD4 T cells [45]. The protective effect 
of HLA-DRB1 ${ }^{*} 13$ could also be explained by this effect. Curiously, several reports have suggested an association of HLA-DRB1* 13 and/or HLA-DQB1 ${ }^{*} 06$ with slow disease progression in human immunodeficiency virus (HIV) infected individuals, meaning that among HIV controllers there is an association between the presence of certain class II HLA alleles and strong CD4 T cell responses [46, 47].

Although different alleles are associated with particular AIDs, the same allele, HLA-DRB1*13, was underrepresented in all six diseases. This difference is statistically significant for the four rheumatic diseases studied. This observation suggests that this allele confers protection to AIDs in general and particularly to rheumatic diseases.

\section{Conflict of Interests}

The authors declare that there is no conflict of interests regarding the publication of this paper.

\section{References}

[1] Y. Shoenfeld, B. Gilburd, M. Abu-Shakra et al., "The mosaic of autoimmunity: genetic factors involved in autoimmune diseases-2008," Israel Medical Association Journal, vol. 10, no. 1, pp. 3-7, 2008.

[2] J.-M. Anaya, L. Gómez, and J. Castiblanco, "Is there a common genetic basis for autoimmune diseases?" Clinical and Developmental Immunology, vol. 13, no. 2-4, pp. 185-195, 2006.

[3] P. Cruz-Tapias, O. M. Pérez-Fernández, A. Rojas-Villarraga, A. Rodríguez-Rodríguez, M.-T. Arango, and J.-M. Anaya, "Shared HLA class II in six autoimmune diseases in Latin America: a meta-analysis," Autoimmune Diseases, vol. 2012, Article ID 569728, 10 pages, 2012.

[4] J. M. Anaya, "The autoimmune tautology," Arthritis Research \& Therapy, vol. 12, no. 6, article 147, 2010.

[5] D. E. Smilek and E. W. St Clair, "Solving the puzzle of autoimmunity: critical questions," F1000Prime Reports, vol. 7, article 17, 2015.

[6] J. Sprent and H. Kishimoto, "The thymus and central tolerance," Transplantation, vol. 72, no. 8, supplement, pp. S25-S28, 2001.

[7] J. A. Bluestone, "Mechanisms of tolerance," Immunological Reviews, vol. 241, no. 1, pp. 5-19, 2011.

[8] S. Tsai and P. Santamaria, "MHC class II polymorphisms, autoreactive T-cells, and autoimmunity," Frontiers in Immunology, vol. 4, article 321, Article ID Article 321, 2013.

[9] T. K. Starr, S. C. Jameson, and K. A. Hogquist, "Positive and negative selection of T cells," Annual Review of Immunology, vol. 21, pp. 139-176, 2003.

[10] E. Palmer, "Negative selection-clearing out the bad apples from the T-cell repertoire," Nature Reviews Immunology, vol. 3, no. 5, pp. 383-391, 2003.

[11] F. Lühder, J. Katz, C. Benoist, and D. Mathis, "Major histocompatibility complex class II molecules can protect from diabetes by positively selecting T cells with additional specificities," Journal of Experimental Medicine, vol. 187, no. 3, pp. 379-387, 1998.

[12] D. Schmidt, J. Verdaguer, N. Averill, and P. Santamaria, "A mechanism for the major histocompatibility complex-linked resistance to autoimmunity," Journal of Experimental Medicine, vol. 186, no. 7, pp. 1059-1075, 1997.
[13] D. Schmidt, A. Amrani, J. Verdaguer, S. Bou, and P. Santamaria, "Autoantigen-independent deletion of diabetogenic $\mathrm{CD} 4{ }^{+}$thymocytes by protective MHC class II molecules," Journal of Immunology, vol. 162, no. 8, pp. 4627-4636, 1999.

[14] S. Tsai, P. Serra, X. Clemente-Casares et al., "Antidiabetogenic MHC class II promotes the differentiation of MHCpromiscuous autoreactive $\mathrm{T}$ cells into $\mathrm{FOXP}^{+}$regulatory $\mathrm{T}$ cells," Proceedings of the National Academy of Sciences of the United States of America, vol. 110, no. 9, pp. 3471-3476, 2013.

[15] K. W. Wucherpfennig and D. Sethi, "T cell receptor recognition of self and foreign antigens in the induction of autoimmunity," Seminars in Immunology, vol. 23, no. 2, pp. 84-91, 2011.

[16] D. L. Morris, K. E. Taylor, M. M. A. Fernando et al., "Unraveling multiple MHC gene associations with systemic lupus erythematosus: model choice indicates a role for HLA alleles and non-HLA genes in Europeans," The American Journal of Human Genetics, vol. 91, no. 5, pp. 778-793, 2012.

[17] C. Vasconcelos, C. Carvalho, B. Leal et al., "HLA in Portuguese systemic lupus erythematosus patients and their relation to clinical features," Annals of the New York Academy of Sciences, vol. 1173, pp. 575-580, 2009.

[18] H. Furukawa, A. Kawasaki, S. Oka et al., "Human leukocyte antigens and systemic lupus erythematosus: a protective role for the HLA-DR6 alleles DRB1 ${ }^{*} 13: 02$ and *14:03," PLoS ONE, vol. 9, no. 2, Article ID e87792, 2014.

[19] P. Y. P. C. Ho, A. Barton, J. Worthington et al., "Investigating the role of the HLA-Cw* 06 and HLA-DRB1 genes in susceptibility to psoriatic arthritis: comparison with psoriasis and undifferentiated inflammatory arthritis," Annals of the Rheumatic Diseases, vol. 67, no. 5, pp. 677-682, 2008.

[20] I. Shawkatová, J. Javor, Z. Párnická et al., "HLA-C, DRB1 and DQB1 alleles involved in genetic predisposition to psoriasis vulgaris in the Slovak population," Folia Microbiologica, vol. 58, no. 4, pp. 319-324, 2013.

[21] H. Furukawa, S. Oka, K. Shimada, A. Hashimoto, and S. Tohma, "Human leukocyte antigen polymorphisms and personalized medicine for rheumatoid arthritis," Journal of Human Genetics, 2015.

[22] S. T. Flam, R. Gunnarsson, T. Garen, B. A. Lie, and O. Molberg, "The HLA profiles of mixed connective tissue disease differ distinctly from the profiles of clinically related connective tissue diseases," Rheumatology, vol. 54, no. 3, pp. 528-535, 2015.

[23] D. D. Gladman, T. N. Kung, F. Siannis, F. Pellett, V. T. Farewell, and P. Lee, "HLA markers for susceptibility and expression in scleroderma," Journal of Rheumatology, vol. 32, no. 8, pp. 14811487, 2005.

[24] B. A. C. Cree, "Multiple sclerosis genetics," Handbook of Clinical Neurology, vol. 122, pp. 193-209, 2014.

[25] A. M. Silva, C. Pereira, A. Bettencourt et al., "The role of HLADRB1 alleles on susceptibility and outcome of a Portuguese Multiple Sclerosis population," Journal of the Neurological Sciences, vol. 258, no. 1-2, pp. 69-74, 2007.

[26] N. Avidan, R. Le Panse, S. Berrih-Aknin, and A. Miller, "Genetic basis of myasthenia gravis-a comprehensive review," Journal of Autoimmunity, vol. 52, pp. 146-153, 2014.

[27] S. A. Miller, D. D. Dykes, and H. F. Polesky, "A simple salting out procedure for extracting DNA from human nucleated cells," Nucleic Acids Research, vol. 16, no. 3, article 1215, 1988.

[28] O. Olerup and H. Zetterquist, "HLA-DR typing by PCR amplification with sequence-specific primers (PCR-SSP) in 2 hours: an alternative to serological DR typing in clinical practice 
including donor-recipient matching in cadaveric transplantation," Tissue Antigens, vol. 39, no. 5, pp. 225-235, 1992.

[29] G. Candore, D. Lio, G. Colonna Romano, and C. Caruso, "Pathogenesis of autoimmune diseases associated with 8.1 ancestral haplotype: effect of multiple gene interactions," Autoimmunity Reviews, vol. 1, no. 1-2, pp. 29-35, 2002.

[30] J. A. Collado, C. Guitart, M. Teresa Ciudad, I. Alvarez, and D. Jaraquemada, "The repertoires of peptides presented by MHC-II in the thymus and in peripheral tissue: a clue for autoimmunity?" Frontiers in Immunology, vol. 4, article 442, 2013.

[31] A. Bruno and H. A. Lima, "HLA-A, -C, -B, and -DRB1 allelic and haplotypic diversity in bone marrow volunteer donors from northern Portugal," Organs, Tissues \& Cells, vol. 16, pp. 19-26, 2013.

[32] K. R. Jun, S.-E. Choi, C.-H. Cha et al., "Meta-analysis of the association between HLA-DRB1 allele and rheumatoid arthritis susceptibility in Asian populations," Journal of Korean Medical Science, vol. 22, no. 6, pp. 973-980, 2007.

[33] S. Oka, H. Furukawa, A. Kawasaki et al., "Protective effect of the HLA-DRB1*13:02 allele in Japanese rheumatoid arthritis patients," PLoS ONE, vol. 9, no. 6, Article ID e99453, 2014.

[34] F. Uçar, M. Karkucak, E. Alemdaroğlu et al., "HLA-DRB1 allele distribution and its relation to rheumatoid arthritis in eastern Black Sea Turkish population," Rheumatology International, vol. 32, no. 4, pp. 1003-1007, 2012.

[35] J. Tuokko, S. Nejentsev, R. Luukkainen, A. Toivanen, and J. Ilonen, "HLA haplotype analysis in Finnish patients with rheumatoid arthritis," Arthritis and Rheumatism, vol. 44, no. 2, pp. 315-322, 2001.

[36] D. van der Woude, B. A. Lie, E. Lundström et al., "Protection against anti-citrullinated protein antibody-positive rheumatoid arthritis is predominantly associated with HLA-DRB1 ${ }^{*} 1301$ : a meta-analysis of HLA-DRB1 associations with anti-citrullinated protein antibody-positive and anti-citrullinated protein antibody-negative rheumatoid arthritis in four European populations," Arthritis \& Rheumatism, vol. 62, no. 5, pp. 1236-1245, 2010.

[37] A. H. M. van der Helm-van Mil, T. W. J. Huizinga, G. M. T. Schreuder, F. C. Breedveld, R. R. P. de Vries, and R. E. M. Toes, "An independent role of protective HLA class II alleles in rheumatoid arthritis severity and susceptibility," Arthritis and Rheumatism, vol. 52, no. 9, pp. 2637-2644, 2005.

[38] P. M. Stassen, J. W. Cohen-Tervaert, S. P. M. Lems, B. G. Hepkema, C. G. M. Kallenberg, and C. A. Stegeman, "HLA-DR4, DR13(6) and the ancestral haplotype A1B8DR3 are associated with ANCA-associated vasculitis and Wegener's granulomatosis," Rheumatology, vol. 48, no. 6, pp. 622-625, 2009.

[39] L. Michou, P. Croiseau, E. Petit-Teixeira et al., "Validation of the reshaped shared epitope HLA-DRB1 classification in rheumatoid arthritis," Arthritis Research and Therapy, vol. 8, no. 3, article R79, 2006.

[40] I. E. van der Horst-Bruinsma, H. Visser, J. M. W. Hazes et al., "HLA-DQ-associated predisposition to and dominant HLADR-associated protection against rheumatoid arthritis," Human Immunology, vol. 60, no. 2, pp. 152-158, 1999.

[41] D. L. Mattey, P. T. Dawes, M. A. Gonzalez-Gay et al., "HLADRB1 alleles encoding an aspartic acid at position 70 protect against development of rheumatoid arthritis," Journal of Rheumatology, vol. 28, no. 2, pp. 232-239, 2001.
[42] J. van Heemst, D. T. Jansen, S. Polydorides et al., "Crossreactivity to vinculin and microbes provides a molecular basis for HLAbased protection against rheumatoid arthritis," Nature Communications, vol. 6, article 6681, 2015.

[43] H. M. Diepolder, M.-C. Jung, E. Keller et al., "A vigorous virusspecific $\mathrm{CD} 4^{+} \mathrm{T}$ cell response may contribute to the association of HLA-DR13 with viral clearance in hepatitis B," Clinical and Experimental Immunology, vol. 113, no. 2, pp. 244-251, 1998.

[44] A. Ramezani, M. R. Hasanjani Roshan, E. Kalantar et al., "Association of human leukocyte antigen polymorphism with outcomes of hepatitis B virus infection," Journal of Gastroenterology and Hepatology, vol. 23, no. 11, pp. 1716-1721, 2008.

[45] C. Fesel, M. Barreto, R. C. Ferreira et al., "Compensatory T-cell regulation in unaffected relatives of SLE patients, and opposite IL-2/CD25-mediated effects suggested by coreferentiality modeling," PLoS ONE, vol. 7, no. 3, Article ID e33992, 2012.

[46] A. L. Ferre, P. W. Hunt, D. H. McConnell et al., "HIV controllers with HLA-DRB1 ${ }^{*} 13$ and HLA-DQB1 06 alleles have strong, polyfunctional mucosal $\mathrm{CD} 4^{+}$T-cell responses," Journal of Virology, vol. 84, no. 21, pp. 11020-11029, 2010.

[47] U. Malhotra, S. Holte, S. Dutta et al., "Role for HLA class II molecules in HIV-1 suppression and cellular immunity following antiretroviral treatment," The Journal of Clinical Investigation, vol. 107, no. 4, pp. 505-517, 2001. 


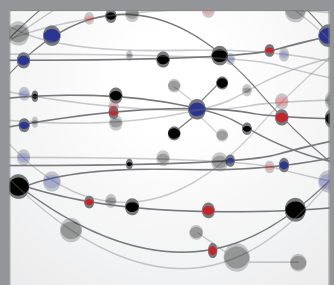

The Scientific World Journal
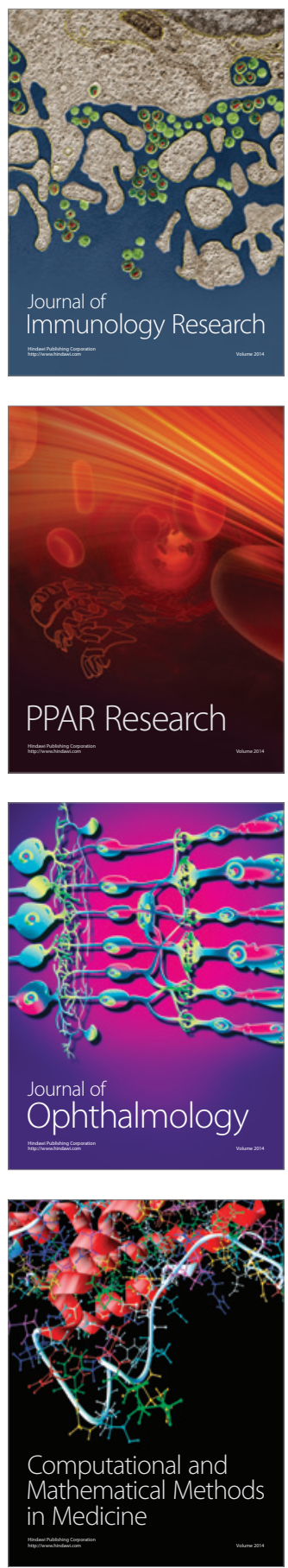

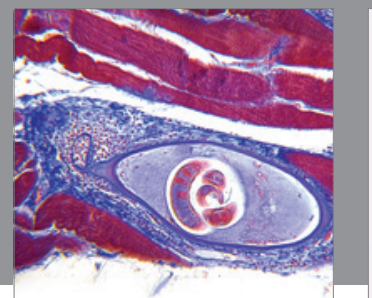

Gastroenterology

Research and Practice
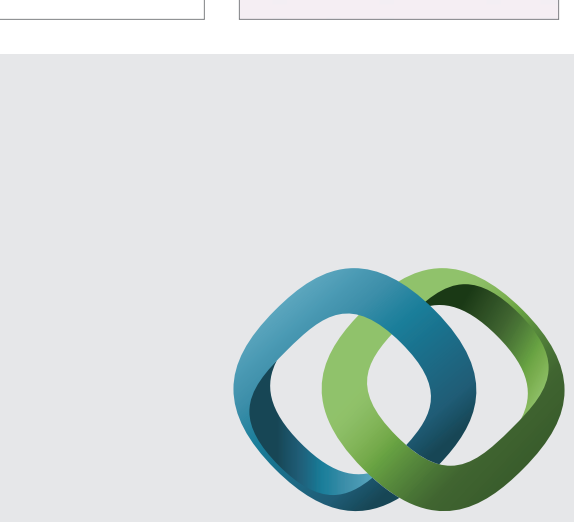

\section{Hindawi}

Submit your manuscripts at

http://www.hindawi.com
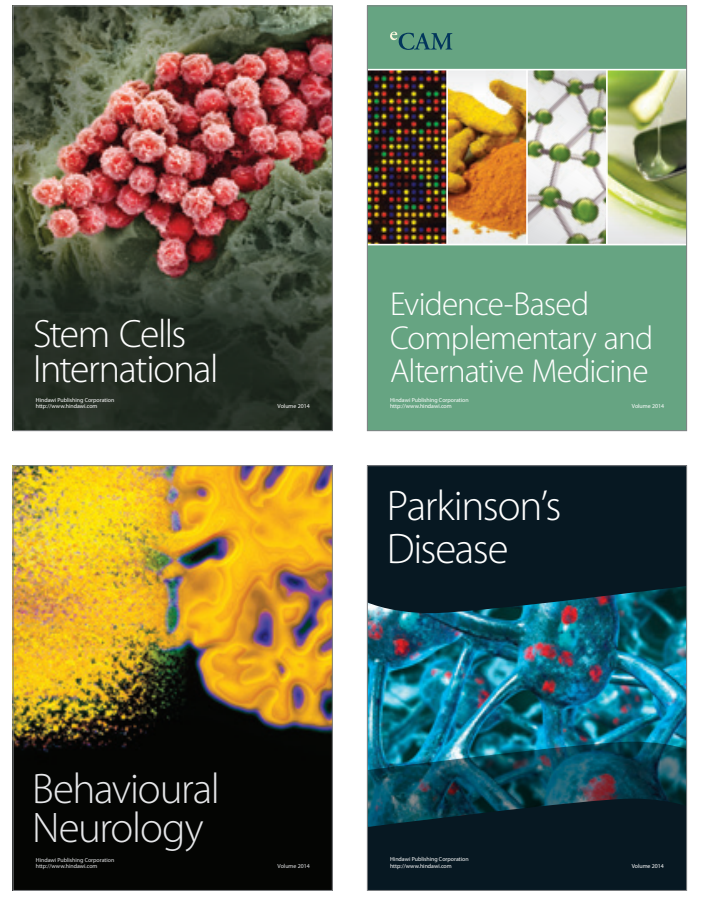
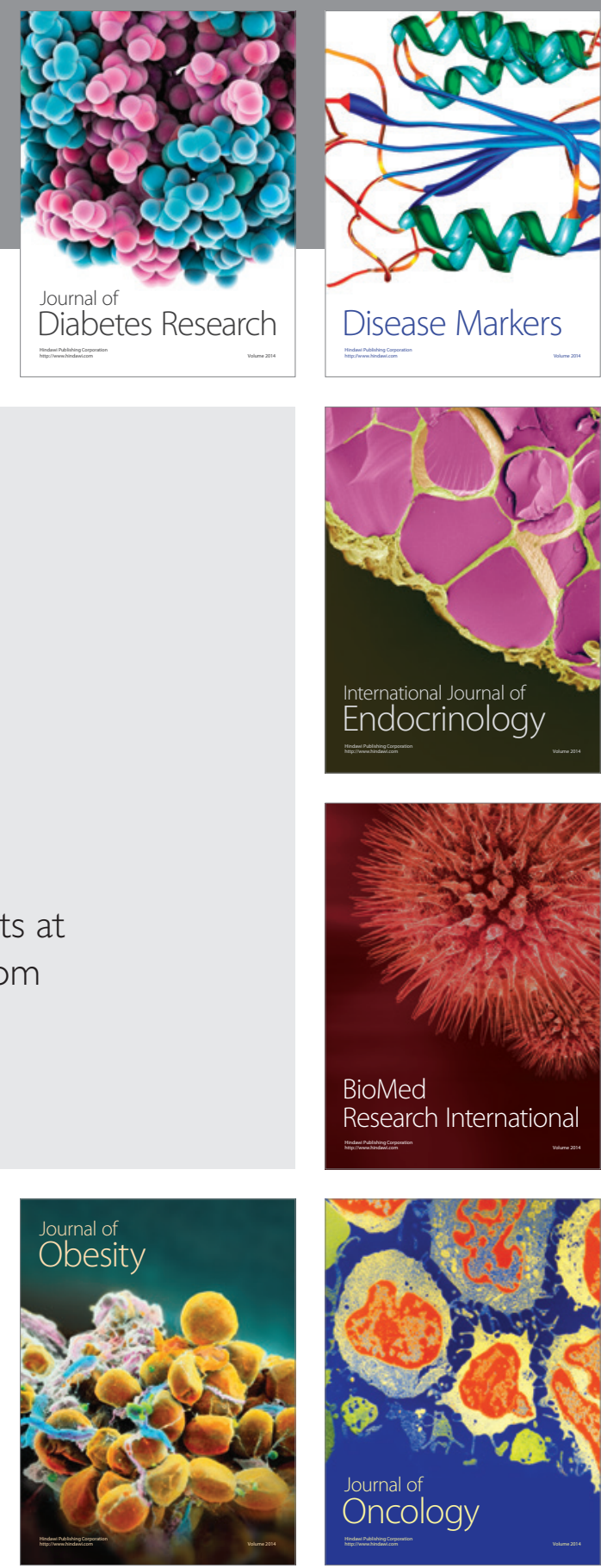

Disease Markers
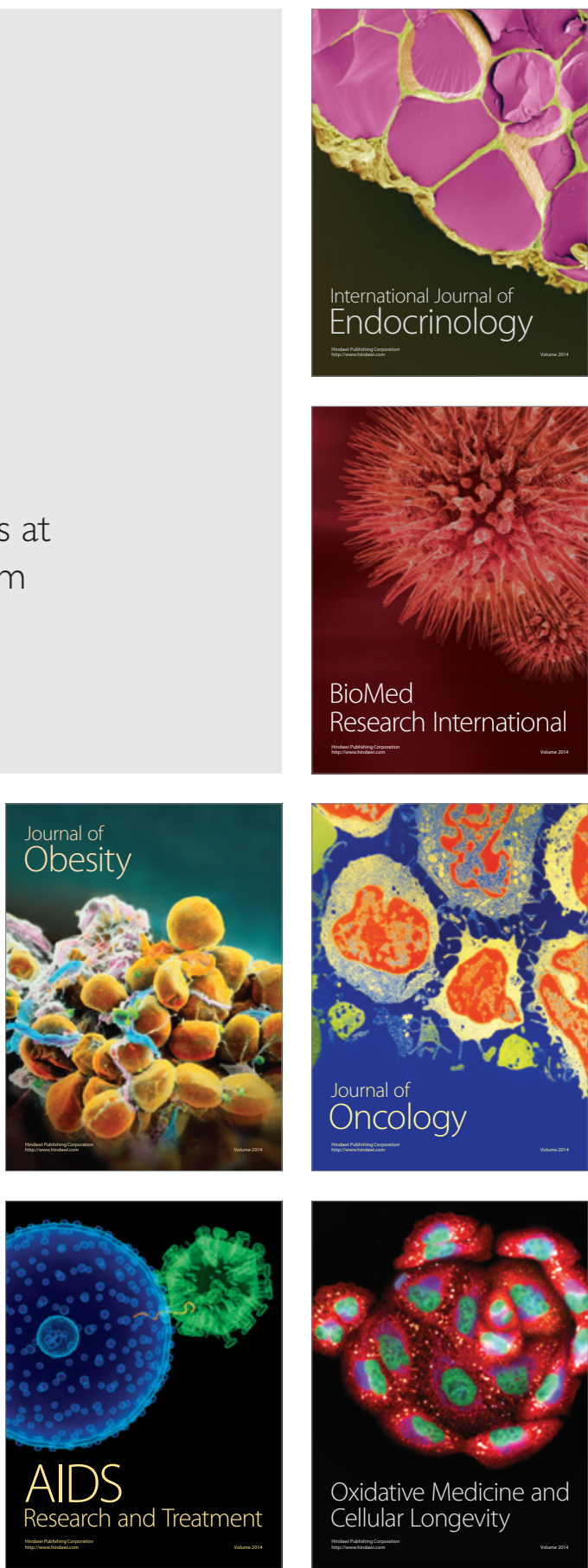